ORIGINAL ARTICLE

\title{
Effect of Early Rehabilitation Treatment on Activities of Daily Living in Patients Receiving Conservative Treatment for Vertebral Compression Fracture
}

\author{
Takaaki Ikeda, RPT, PhD ${ }^{\text {a,b }}$ Tomoto Suzuki, MD, $\mathrm{PhD}^{\mathrm{c}}$ Michiaki Takagi, MD, $\mathrm{PhD}^{\mathrm{c}}$ and \\ Masayasu Murakami, PhD a
}

\begin{abstract}
Objectives: Vertebral compression fractures are common among older people. Currently, knowledge of the effects of early rehabilitation treatment on the recovery of activities of daily living (ADL) in older patients who receive conservative treatment for these fractures is limited. Using the instrumental variable (IV) method, we examined the effects on ADL at discharge of a delay in initiating rehabilitation treatment. Methods: In this retrospective cohort study, data from the Japanese Diagnosis Procedure Combination database were analyzed. The subjects were patients with vertebral compression fracture who had undergone rehabilitation treatment during their hospitalization between 2014 and 2019 in one of the 29 acute-care hospitals in Yamagata Prefecture. We analyzed data from 1706 patients (mean age, 82.1 years). The independent variable was the number of days between hospital admission and the start of rehabilitation treatment, and the outcome was the Barthel index (BI) score at discharge. An IV method was applied, with adjustments for covariates, including demographics and functional status at admission. Results: Most patients started rehabilitation treatment within 3 days of hospital admission. Our IV method showed that the interval between hospital admission and the start of rehabilitation treatment was significantly associated with the BI score at discharge. The coefficient was $-2.71(95 \%$ confidence interval [CI]: -5.06 to -0.35 ). Conclusions: A delay in initiating rehabilitation treatment had a negative effect on ADL at discharge. This result emphasizes the importance of including early rehabilitation treatment in acute care, as recommended by several existing guidelines for the treatment of orthopedic diseases.
\end{abstract}

Key Words: Barthel index; early mobilization; instrumental variable; IV regression

\section{INTRODUCTION}

Vertebral compression fractures are common health problems in older people, and two-thirds of such fractures are asymptomatic. ${ }^{1)}$ However, some patients report serious adverse health-related outcomes, such as pain, ${ }^{2)}$ disability, ${ }^{3)}$ and poor quality of life. ${ }^{4)}$ Vertebral fractures are highly prevalent among patients with osteoporosis, many of whom are older women. ${ }^{3,5)}$ Annually, more than 1 million patients present with vertebral compression fractures globally. Consequently, this type of injury is considered a major public health concern. ${ }^{3)}$ The burden resulting from this fracture type significantly affects both the patients themselves and the societal and health care economies. ${ }^{5)}$

Early rehabilitation treatment is widely recommended and offered to patients with various orthopedic diseases in acute-care hospitals. ${ }^{6-8)}$ Based on previous studies, early rehabilitation treatment is deemed effective in reducing the

Received: June 23, 2021, Accepted: November 4, 2021, Published online: December 9, 2021

${ }^{a}$ Department of Health Policy Science, Graduate School of Medical Science, Yamagata University, Yamagata, Japan

${ }^{b}$ Department of International and Community Oral Health, Tohoku University Graduate School of Dentistry, Miyagi, Japan

c Department of Orthopedic Surgery, Yamagata University Faculty of Medicine, Yamagata, Japan

Correspondence: Takaaki Ikeda, RPT, PhD, Department of Health Policy Science, Graduate School of Medical Science, Yamagata

University, 2-2-2 Iidanishi, Yamagata, Yamagata 990-9585, Japan, E-mail: t.ikeda0110@gmail.com

Copyright (C) 2021 The Japanese Association of Rehabilitation Medicine

(c) (1) $(-)$ This is an open-access article distributed under the terms of the Creative Commons Attribution Non-Commercial No Derivatives (CC BY-NC-ND) 4.0 License. http://creativecommons.org/licenses/by-nc-nd/4.0/ 
length of hospital stay, ${ }^{9}$ the risk of complications, ${ }^{9,10)}$ and in improving activities of daily living (ADL) ${ }^{11)}$ among patients undergoing surgical treatment. Moreover, early rehabilitation treatment is a key component of conservative treatment for patients with vertebral compression fractures. ${ }^{12)}$ In general, conservative treatment of vertebral compression fractures involves the use of non-surgical treatment options such as physical therapy. ${ }^{12)}$ However, data are limited concerning the effects on ADL of early rehabilitation treatment in older patients undergoing conservative rehabilitation treatment for vertebral compression fractures. To the best of our knowledge, only one previous observational study from Japan has examined the effect of early rehabilitation treatment on ADL among older patients who underwent conservative treatment for vertebral compression fractures. ${ }^{13)}$ However, that study could not confirm whether early rehabilitation treatment was effective in improving ADL or whether early rehabilitation treatment was superior to delayed rehabilitation treatment because the study compared patients who did not receive any rehabilitation treatment and those who received early rehabilitation treatment. ${ }^{13)}$ Furthermore, other rehabilitationrelated variables, such as the intensity of the rehabilitation treatment program, which could have resulted in the overestimation of the effects, were not considered. Therefore, it remains unclear whether early rehabilitation treatment is causally related to better ADL at discharge in patients with vertebral compression fractures.

Randomized controlled trials (RCTs) are considered the gold standard method for examining the causal effects of treatments on outcomes of interest. However, RCTs are not always feasible. As a result, several clinical questions, including the effects of early rehabilitation treatment, cannot be answered because of the ethics of unnecessarily delaying rehabilitation treatment. Observational studies have methodological issues, such as endogeneity and unmeasured confounding factors, that lead to biased results. ${ }^{14,15)}$ However, the instrumental variable (IV) approach can help address the residual confounding factors and reverse causation present in observational studies. ${ }^{14,15)}$ Therefore, the IV approach enables the validity of the current observational study to more closely approach that of an RCT. We hypothesized that patients with a delayed start to rehabilitation treatment were likely to have poorer ADL at discharge compared with those who started rehabilitation treatment early. Here, using the IV method, we examined the effects of delay in the initiation of rehabilitation treatment on ADL at discharge in older patients who received conservative rehabilitation treatment of vertebral compression fractures.

\section{MATERIALS AND METHODS}

\section{Data Source}

We used Diagnosis Procedure Combination (DPC) data that are routinely collected in 30 hospitals in the Yamagata Prefecture, a subnational region of Japan. ${ }^{16)}$ The details of the DPC system have been described elsewhere. ${ }^{17)}$ Briefly, data on clinical information (baseline characteristics of the participants) and administrative claims were collected; the data accounted for approximately $90 \%$ of the acute-care hospitalizations for vertebral compression fractures between April 2014 and March 2019 in Yamagata Prefecture. ${ }^{16)}$

\section{Patients}

Patients with vertebral compression fractures who were discharged between April 1, 2014, and March 31, 2019, $(n=4778)$ from 29 hospitals were included in this study. In line with a previous study, ${ }^{13)}$ subjects were identified using the International Classification of Diseases, Tenth Revision (ICD-10), codes S220, S320, and T021. We excluded those who were admitted from another hospital ( $\mathrm{n}=281)$, those who underwent surgery $(\mathrm{n}=674)$, those aged $\leq 64$ years $(\mathrm{n}=458)$, those who died during hospitalization $(\mathrm{n}=31)$, those who remained in hospital for $>30$ days $(\mathrm{n}=1383)$, and those who did not undergo rehabilitation treatment $(\mathrm{n}=245)$. In Japan, the mean length of hospital stay for patients who receive conservative treatment for vertebral compression fractures is approximately 30 days. ${ }^{18)}$ Therefore, we excluded those patients who remained in hospital for $>30$ days. As a result, 1706 patients were included in the primary analysis (Fig. 1).

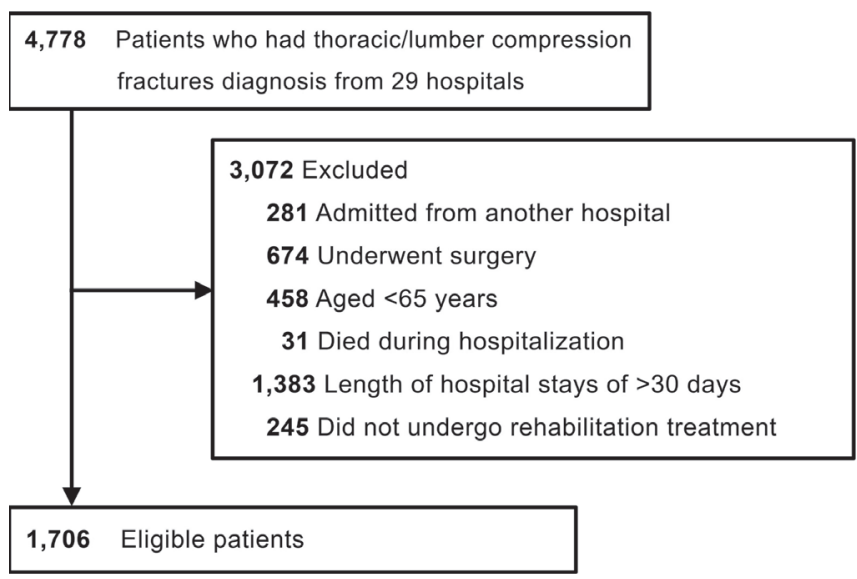

Fig. 1. Flow diagram of the patient selection. 


\section{Independent and Outcome Variables}

The independent variable was the interval between hospital admission and the start of rehabilitation treatment. We considered this variable to be continuous because there was no clear information on the ideal cut-off day for early rehabilitation treatment. The outcome variable was the ability to perform ADL at discharge, which was evaluated using the Barthel index (BI) scores. The BI comprises a 10-item scale that is used to evaluate abilities such as eating, grooming, bowel and bladder control, using the toilet, transfer, mobility, dressing, bathing, and climbing stairs, ${ }^{19)}$ and its validity and reliability have been confirmed previously. ${ }^{20)}$ The BI score, which ranges from 0 to 100 , is the sum of the points allotted to each of the 10 items (i.e., 5, 10, or 15 points, depending on the item). Higher scores indicate a better ability to perform ADL. ${ }^{19)}$ The minimal detectable change in the BI score for older patients is reportedly 15 points. $^{21)}$

\section{Covariates}

The following variables were considered as covariates and were adjusted for in the analysis: age, sex, site of fracture (thoracic vertebra, lumbar vertebra, or both), BI score at admission, frequency of in-hospital rehabilitation treatments, intensity of in-hospital rehabilitation treatments, Charlson comorbidity index score, ${ }^{22)}$ residence before admission (home or nursing facility), body mass index (BMI) at admission $\left(<18.5,18.5-24.9,25.0-29.9\right.$, or $\left.\geq 30.0 \mathrm{~kg} / \mathrm{m}^{2}\right)$, use of home health care services before admission (yes or no), level of dementia (no dementia, mild to moderate dementia, or severe dementia), ${ }^{11)}$ length of hospital stay, and admission by ambulance.

The BMI was calculated as the weight in kilograms divided by the height in meters squared. The patient's dementia level was evaluated using the scale originally developed by the Japanese Ministry of Health, Labour, and Welfare that was used in a previous study. ${ }^{11}$ The validity and reliability of dementia level detection were confirmed previously. ${ }^{23)}$ On the basis of a previous study, ${ }^{11)}$ we calculated the frequency of in-hospital rehabilitation treatment sessions ( $\leq 3.0,3.1-4.0$, $4.1-5.0,5.1-6.0$, or 6.1-7.0 days per week) and the intensity (average daily time) of in-hospital rehabilitation treatment (20-39, 40-59, or $\geq 60 \mathrm{~min} /$ day).

\section{Statistical Analyses}

First, we performed descriptive analyses of the patients' characteristics, the intervals from admission to the start of rehabilitation treatment, and outcomes (BI score at discharge). Second, we used the two-stage, least squares, instrumental variable (IV) approach with consideration of reverse causation and residual confounders (e.g., socioeconomic status). ${ }^{14,15)}$ The IV approach enabled us to estimate the causal effect of the independent variable on outcomes, as is usually done in RCTs. ${ }^{14,15)}$

Generally, conventional regression models are based on an important assumption: the absence of correlation between the error term (includes unmeasured confounders) and the independent variables. However, in practical analyses, it is difficult to satisfy this assumption because there are simultaneous decision problems and missing variables. Simultaneous decision problems include reverse causality, which possibly occurs when the control variables come with simultaneous outcomes. Independent variables that do not satisfy this condition are called endogenous variables, whereas variables that do are called exogenous variables. If an endogenous variable exists, it can be resolved if there is an "instrumental" variable that is correlated with the endogenous variable but not with the error term. ${ }^{14,15)}$ In other words, causality can be inferred if there is an IV that correctly meets the previously mentioned assumption. In RCTs, it can be considered that the treatment assignment is a kind of IV. In RCTs, because the treatment assignment is random, this IV would not directly affect the outcome, and the condition that it is not correlated with the error term is properly met. Therefore, we applied the IV approach to allow the current observational study to mimic an RCT as closely as possible. In the current study, we used (pre) weekend admission (defined as admission on a Friday or Saturday) as the IV; this variable has frequently been used in previous studies. ${ }^{24,25)}$ Generally, patients who are admitted on a Friday or Saturday are more likely to start rehabilitation treatment later than other patients, and, overall, the date of hospital admission due to fractures was likely to be randomly distributed. The two-stage least squares IV model was used. First, we regressed the interval from admission to the start of rehabilitation treatment on the IV variable (admission on a Friday or Saturday) and the set of covariates. Then, we regressed our outcome on the predicted value from the previously mentioned regression model and the set of covariates. The $F$-test was used to evaluate the strength of the instruments. If $F$ was greater than 10, the instruments were considered adequately strong. ${ }^{15)}$ We used cluster robust standard errors to account for the fact that patients were nested within hospitals.

For missing data, we used the multiple imputation method. Incomplete variables were imputed with the chained equation method using all previously mentioned covariates. We also added dummy variables for hospitals to the estimation. 
The results from 100 imputed datasets were combined using Rubin's rule. ${ }^{26)}$

In our dataset, approximately a quarter of the patients were excluded because of a length of hospital stay longer than 30 days (Fig. 1). These likely included patients with more severe fractures that might have required a longer period of hospitalization. Moreover, approximately $40 \%$ of BI data at admission were missing, and the distribution of the missing data might not have been random. Our data also lacked information on the severity of pain or weakness before admission, and patients with these severe conditions were more likely to have longer hospital stays. Consequently, we conducted several types of sensitivity analyses to confirm the robustness of our results, i.e., analyses using data from patients admitted to the hospital for $\leq 60$ days and $\leq 90$ days, complete case analysis, best-case imputation analysis, and worst-case imputation analysis. Best-case imputation is a type of analysis in which the missing values for BI at admission, BMI, and use of home health care services were set to 100 (good score), 18.5-24.9, and no, respectively. Additionally, the missing values for BI at discharge were set to 100 (good score), and the same analysis was performed. In contrast, worst-case imputation involved the missing values for BI at admission, BMI, and use of home health care services being set to 0 (poor score), $<18.5$, and yes, respectively. Additionally, the missing values for BI at discharge were set to 0 (poor score), and the same analysis was performed. We also conducted (1) subgroup analyses in which patients with osteoporosis were included, (2) subgroup analysis in which only patients aged $\geq 75$ years were included, and (3) another sensitivity analysis in which BI improvement (i.e., BI at discharge - BI at admission) was used as the outcome. We identified osteoporosis patients using physician diagnoses (e.g., osteoporosis) and medication use (e.g., elcatonin) during hospitalization. All analyses were conducted using Stata version 16.1. This study was approved by the ethics committee of Yamagata University (approval no. 2019-101). The requirement for informed consent was waived because of the anonymous nature of the data.

\section{RESULTS}

The characteristics and health status of the patients are shown in Table 1. Most patients were women, were aged $\geq 75$ years, and presented with a lumbar vertebral fracture. The rehabilitation-related variables and the $\mathrm{BI}$ score at discharge are shown in Table 2. The majority of patients (59.4\%) started rehabilitation treatment within 3 days of admission. Furthermore, the most common frequency of in-hospital rehabilitation treatment was 4.1-5.0 days/week, and the most common intensity of in-hospital rehabilitation treatment was 20-39 min/day. The patients' characteristics, rehabilitationrelated variables, and BI scores according to our IV variable are summarized in Table 3. Overall, no significant differences in the aforementioned parameters were observed between the Sunday-Thursday and Friday-Saturday [(pre) weekend] admission groups, except for the frequency of rehabilitation treatment.

The results of the IV regression models are shown in Table 4. The $F$-statistic was 20.1 , thereby indicating a sufficient correlation between the IV approach and the independent variable. The interval between admission and the start of rehabilitation treatment was significantly associated with the BI score at discharge after adjusting for all covariates. The coefficient was -2.71 (95\% confidence interval [CI]: -5.06 to -0.35$)$. Moreover, subgroup analyses targeting patients with osteoporosis also illustrated that the interval between admission and the start of rehabilitation treatment was significantly associated with $\mathrm{BI}$ at discharge (coefficient $=-4.89$ [95\% CI $=-9.69$ to -0.10$]$, Supplementary Table 1). Similar results were observed when we analyzed patients hospitalized for $\leq 60$ days and $\leq 90$ days (Supplementary Tables 2 and 3). The coefficients were $-2.02(95 \% \mathrm{CI}:-3.84$ to -0.20$)$ and -1.93 (95\% CI: -3.90 to -0.02$)$, respectively. Sensitivity analysis in which the improvement in BI was used as the outcome also showed that the interval between admission and the start of rehabilitation treatment was significantly associated with BI improvement among patients hospitalized for $\leq 30$ days (coefficient $=-2.72[95 \% \mathrm{CI}=-5.08$ to -0.36$]$, Supplementary Table 4). Similarly, subgroup analyses in which only patients aged $\geq 75$ years were included showed that the interval between admission and the start of rehabilitation treatment had a similar effect on BI at discharge, although the difference was not statistically significant (coefficient $=-2.68[95 \% \mathrm{CI}=-5.51$ to 0.15$]$; Supplementary

\section{Table 5).}

The associations between the other rehabilitation-related variables (i.e., the frequency of rehabilitation treatment during hospitalization and the intensity of rehabilitation treatment during hospitalization) and the BI score at discharge in the IV regression model are presented in Table 4. The BI score at discharge was significantly higher in the group that received rehabilitation treatment for $40-59$ and $\geq 60 \mathrm{~min} /$ day than in the group that received rehabilitation treatment for 20-39 min/day (lowest intensity). The coefficients were 7.28 (95\% CI: 1.83-12.72) and 10.24 (95\% CI: 3.53-16.94), respectively. In contrast, no significant associations were 
Table 1. Characteristics of patients with vertebral compression fractures

\begin{tabular}{|c|c|c|}
\hline Characteristic & $\begin{array}{l}\text { Total number of patients } \\
\qquad(\mathrm{n}=1706)\end{array}$ & \\
\hline Age (years) & Total & $\%$ \\
\hline $65-74$ & 291 & 17.1 \\
\hline $75-84$ & 713 & 41.8 \\
\hline $85-94$ & 655 & 38.4 \\
\hline$\geq 95$ & 47 & 2.8 \\
\hline Female participants & 1199 & 70.3 \\
\hline \multicolumn{3}{|l|}{ Body mass index, $\mathrm{kg} / \mathrm{m}^{2}$} \\
\hline$<18.5$ & 222 & 13.0 \\
\hline $18.5-24.9$ & 935 & 54.8 \\
\hline $25.0-29.9$ & 207 & 12.1 \\
\hline$\geq 30$ & 35 & 2.1 \\
\hline Missing data & 307 & 18.0 \\
\hline \multicolumn{3}{|l|}{ Level of dementia } \\
\hline None & 1111 & 65.1 \\
\hline Mild to moderate & 549 & 32.2 \\
\hline Severe & 46 & 2.7 \\
\hline \multicolumn{3}{|l|}{ Charlson comorbidity index score } \\
\hline $0-1$ & 1544 & 90.5 \\
\hline$\geq 2$ & 162 & 9.5 \\
\hline \multicolumn{3}{|l|}{ Site of fracture } \\
\hline Thoracic vertebra & 528 & 31.0 \\
\hline Lumbar vertebra & 1012 & 59.3 \\
\hline Thoracic and lumbar vertebra & 166 & 9.7 \\
\hline Diagnosis of osteoporosis or prescribed medications related to osteoporosis & 748 & 43.9 \\
\hline Admission by ambulance & 735 & 43.1 \\
\hline Nursing facility resident & 67 & 3.9 \\
\hline \multicolumn{3}{|l|}{ Barthel index at admission } \\
\hline$<100$ (dependent) & 815 & 47.8 \\
\hline 100 (independent) & 158 & 9.3 \\
\hline Missing data & 733 & 43.0 \\
\hline \multicolumn{3}{|l|}{ Use of home health care services } \\
\hline Yes & 81 & 4.8 \\
\hline No & 1507 & 88.3 \\
\hline Missing data & 118 & 6.9 \\
\hline
\end{tabular}

Because of rounding, percentages do not add up to exactly $100 \%$.

observed between the frequency of rehabilitation treatment during hospitalization and the BI score at discharge.

\section{DISCUSSION}

To the best of our knowledge, this is the first study to demonstrate the effects on ADL at discharge of a delay in initiating rehabilitation treatment among older patients who underwent conservative rehabilitation treatment for vertebral compression fractures. A significant effect was observed in terms of the BI score at discharge and of the improvement in BI score at discharge.

A previous observational study from Japan showed that early rehabilitation treatment was effective in improving BI scores among older patients who underwent conservative treatment for vertebral compression fractures. In that study, 
Table 2. Rehabilitation-related variables and Barthel index score at discharge

\begin{tabular}{lcc}
$\begin{array}{l}\text { Rehabilitation-related } \\
\text { variable }\end{array}$ & $\begin{array}{c}\text { Number of participants } \\
\left(\mathrm{n}=1381^{*}\right)\end{array}$ & $\begin{array}{c}\text { BI score at discharge, median } \\
(25 \text { th-75th percentiles })\end{array}$ \\
\hline Interval from admission to rehabilitation (per extra day) & $70(50-100)$ \\
1 & 68 & $70(45-100)$ \\
2 & 510 & $70(50-100)$ \\
3 & 242 & $70(45-100)$ \\
4 & 177 & $80(50-100)$ \\
5 & 119 & $65(35-100)$ \\
6 & 67 & $80(45-100)$ \\
$\geq 7$ & 198 & $75(40-95)$ \\
\hline Frequency of rehabilitation treatment during hospitalization $($ days $/$ week $)$ \\
$\leq 3.0$ & 93 & $70(40-100)$ \\
$3.1-4.0$ & 226 & $75(45-100)$ \\
$4.1-5.0$ & 599 & $70(50-100)$ \\
$5.1-6.0$ & 337 & $70(50-95)$ \\
$6.1-7.0$ & 126 & \\
\hline
\end{tabular}

Intensity of rehabilitation treatment during hospitalization (min/day of rehabilitation treatment)

$\begin{array}{lrl}20-39 & 1001 & 65(40-95) \\ 40-59 & 246 & 85(50-100) \\ \geq 60 & 134 & 90(65-100)\end{array}$

BI, Barthel index.

*We excluded 325 participants who lacked information regarding the BI score at discharge.

Kobata et al. compared patients who did not receive any rehabilitation treatment with those who received early rehabilitation treatment (defined as rehabilitation treatment within 3 days of admission). ${ }^{13)}$ Because of its design, that study could not confirm whether early rehabilitation treatment was effective in improving ADL at discharge or whether early rehabilitation treatment was superior to delayed rehabilitation treatment. Furthermore, other rehabilitation-related variables, such as the intensity of the rehabilitation treatment program (which could have resulted in the overestimation of the effects) were not considered. Indeed, the present study showed that a higher intensity of rehabilitation treatment per day was significantly associated with better ADL at discharge. Moreover, Kobata et al. excluded those patients whose BI was missing, possibly indicating that their results were biased toward those with mild symptoms. Indeed, in the current study, patients who arrived by ambulance and those with lower BI scores at discharge were more likely to have missing data for the BI at admission (Supplementary Table 6). Furthermore, these two variables were moderately correlated with the BI at admission (Supplementary Table 7). The findings of the current study, therefore, have added new robust pieces of evidence showing that early rehabilitation treatment is associated with better ADL at discharge in patients with vertebral compression fractures who received rehabilitation treatment during hospitalization.

The positive effect of early rehabilitation treatment during hospitalization has been observed in various orthopedic diseases, which is in accordance with the findings of the present study. ${ }^{9-11,27)}$ We showed that a 1-day delay in starting rehabilitation treatment was associated with a decline of 2.7 points in the BI score at discharge among patients who were admitted on Friday or Saturday. The IV approach, which helped the current observational study more closely mimic an RCT, was theoretically considered to overcome unmeasured confounders, including patients' socioeconomic status and pre-fracture function. ${ }^{14,15)}$ Furthermore, a mid-term effect (a median of 19 days in hospital) of early rehabilitation treatment on ADL was observed in the present study. The effect of early rehabilitation treatment was more likely to be maintained when patients who were in the hospital for $\leq 60$ days and $\leq 90$ days were included in the analysis (Supplementary Tables 2 and 3). Therefore, the effect of early rehabilitation treatment likely persist over the mid- 
Table 3. Characteristics of the patients with vertebral compression fractures according to the instrumental variable

\begin{tabular}{|c|c|c|c|}
\hline Characteristics & $\begin{array}{l}\text { Sunday-Thursday } \\
\text { admission }(\mathrm{n}=1284)\end{array}$ & $\begin{array}{c}\text { Friday or Saturday } \\
\text { [(pre) weekend }] \\
\text { admission }(n=422)\end{array}$ & P-value* \\
\hline \multicolumn{4}{|l|}{ Age (years) } \\
\hline $65-74$ & $233(18.2)$ & $58(13.7)$ & \multirow{4}{*}{0.08} \\
\hline $75-84$ & $542(42.1)$ & $171(40.5)$ & \\
\hline $85-94$ & $475(37.0)$ & $180(42.7)$ & \\
\hline$\geq 95$ & $34(2.7)$ & $13(3.1)$ & \\
\hline Female participants & $900(70.1)$ & $299(70.9)$ & 0.77 \\
\hline \multicolumn{4}{|l|}{ Body mass index, $\mathrm{kg} / \mathrm{m}^{2}$} \\
\hline$<18.5$ & $167(13.0)$ & $55(13.0)$ & \multirow{5}{*}{0.43} \\
\hline $18.5-24.9$ & $712(55.5)$ & $223(52.8)$ & \\
\hline $25.0-29.9$ & $161(12.5)$ & $46(10.9)$ & \\
\hline$\geq 30$ & $25(2.0)$ & $10(2.4)$ & \\
\hline Missing data & $219(17.1)$ & $88(20.9)$ & \\
\hline \multicolumn{4}{|l|}{ Level of dementia } \\
\hline None & $837(65.2)$ & $274(64.9)$ & \multirow{3}{*}{0.87} \\
\hline Mild to moderate & $411(32.0)$ & $138(32.7)$ & \\
\hline Severe & $36(2.8)$ & $10(2.4)$ & \\
\hline \multicolumn{4}{|l|}{ Charlson comorbidity index score } \\
\hline $0-1$ & $1160(90.3)$ & $384(91.0)$ & \multirow{2}{*}{0.69} \\
\hline$\geq 2$ & $124(9.7)$ & $38(9.0)$ & \\
\hline \multicolumn{4}{|l|}{ Site of fracture } \\
\hline Thoracic vertebra & $394(30.7)$ & $134(31.8)$ & \multirow{3}{*}{0.92} \\
\hline Lumbar vertebra & $765(60.0)$ & $247(58.5)$ & \\
\hline Thoracic and lumbar vertebra & $125(9.7)$ & $41(9.7)$ & \\
\hline $\begin{array}{l}\text { Diagnosis of osteoporosis or prescribed medications related to } \\
\text { osteoporosis }\end{array}$ & $564(43.9)$ & $184(43.6)$ & 0.91 \\
\hline Admission by ambulance & $539(42.0)$ & $196(46.5)$ & 0.11 \\
\hline Nursing facility resident & $49(3.8)$ & $18(4.3)$ & 0.68 \\
\hline \multicolumn{4}{|l|}{ Barthel index at admission } \\
\hline$<100$ (dependent) & $617(48.1)$ & $198(46.9)$ & \multirow{3}{*}{0.58} \\
\hline 100 (independent) & $123(9.6)$ & $35(8.3)$ & \\
\hline Missing data & $544(42.4)$ & $189(44.8)$ & \\
\hline \multicolumn{4}{|l|}{ Barthel index at discharge } \\
\hline$<100$ (dependent) & $737(57.4)$ & $259(61.4)$ & \multirow{3}{*}{0.09} \\
\hline 100 (independent) & $306(23.8)$ & $79(18.7)$ & \\
\hline Missing data & $241(18.8)$ & $84(19.9)$ & \\
\hline \multicolumn{4}{|l|}{ Interval from admission to rehabilitation (days) } \\
\hline$\leq 1$ & $67(5.2)$ & $21(5.0)$ & \multirow{7}{*}{$<0.01$} \\
\hline 2 & $566(44.1)$ & $50(11.9)$ & \\
\hline 3 & $242(18.9)$ & $54(12.8)$ & \\
\hline 4 & $93(7.2)$ & $124(29.4)$ & \\
\hline 5 & $81(6.3)$ & $70(16.6)$ & \\
\hline 6 & $52(4.1)$ & $32(7.6)$ & \\
\hline$\geq 7$ & $183(14.3)$ & $71(16.8)$ & \\
\hline \multicolumn{4}{|c|}{ Frequency of rehabilitation treatment during hospitalization (days/week) } \\
\hline$\leq 3$ & $96(7.5)$ & $25(5.9)$ & \multirow{5}{*}{$<0.01$} \\
\hline $3.1-4.0$ & $224(17.5)$ & $65(15.4)$ & \\
\hline $4.1-5.0$ & $578(45.0)$ & $161(38.2)$ & \\
\hline $5.1-6.0$ & $275(21.4)$ & $128(30.3)$ & \\
\hline $6.1-7.0$ & $111(8.6)$ & $43(10.2)$ & \\
\hline \multicolumn{4}{|c|}{ Intensity of rehabilitation treatment during hospitalization ( $\mathrm{min} /$ day of rehabilitation treatment) } \\
\hline 20-39 & $940(73.2)$ & $313(74.2)$ & \\
\hline $40-59$ & $227(17.7)$ & $70(16.6)$ & 0.88 \\
\hline$\geq 60$ & $117(9.1)$ & $39(9.2)$ & \\
\hline Use of home health care services & & & \\
\hline Yes & $60(4.7)$ & $21(5.0)$ & \\
\hline No & $1138(88.6)$ & $369(87.4)$ & 0.79 \\
\hline Missing data & $86(67)$ & $32(76)$ & \\
\hline
\end{tabular}

Values are presented as number and percentages. Because of rounding, percentages do not add up to exactly $100 \%$.

*Chi-squared test was performed. 
Table 4. Imputed data of rehabilitation-related variables with Barthel index score at discharge

\begin{tabular}{|c|c|c|c|c|}
\hline Variables & $\beta$ & \multicolumn{2}{|c|}{$95 \% \mathrm{CI}$} & $\mathrm{P}$-value \\
\hline Interval from admission to rehabilitation (per extra day) & -2.71 & -5.06 & -0.35 & 0.02 \\
\hline \multicolumn{5}{|c|}{ Frequency of rehabilitation treatment during hospitalization (days/week) } \\
\hline$\leq 3$ & Ref. & & & \\
\hline $3.1-4.0$ & 0.79 & -4.30 & 5.87 & 0.76 \\
\hline $4.1-5.0$ & -1.24 & -6.72 & 4.23 & 0.66 \\
\hline $5.1-6.0$ & -0.64 & -9.41 & 8.13 & 0.89 \\
\hline $6.1-7.0$ & -0.83 & -13.03 & 11.37 & 0.89 \\
\hline \multicolumn{5}{|c|}{ Intensity of rehabilitation treatment during hospitalization (min/day of rehabilitation treatment) } \\
\hline $20-39$ & Ref. & & & \\
\hline $40-59$ & 7.28 & 1.83 & 12.72 & 0.01 \\
\hline$\geq 60$ & 10.24 & 3.53 & 16.94 & $<0.01$ \\
\hline
\end{tabular}

CI confidence interval.

The model was adjusted for age, sex, site of fracture, Barthel index score at admission, Charlson comorbidity index score, residence before admission, BMI at admission, use of home health care services before admission, level of dementia, length of hospital stay, and admission by ambulance.

Clustering of standard errors within hospitals was considered.

$F$-statistic $=20.1$.

term (approximately 2-3 months from hospital admission). Furthermore, subgroup analyses indicated that the effect of delayed rehabilitation treatment was larger in patients with osteoporosis, thereby emphasizing the importance of introducing early rehabilitation treatment for these patients

\section{(Supplementary Table 1).}

The fact that bed rest results in loss of muscle mass in older individuals may be the mechanism underlying the effect of early rehabilitation treatment on ADL. ${ }^{28)}$ In general, rehabilitation treatment programs for acute vertebral compression fractures comprise (1) therapeutic exercise, which aims to reduce pain and improve bone density, and (2) education, which aims to improve posture and body mechanics to reduce vertical compressive loads and prevent future fractures. ${ }^{29)}$ Patients with delayed rehabilitation treatment were more likely to have worsened ADL because they had had no opportunity to improve their function. Consequently, early rehabilitation treatment is necessary for patients with acute vertebral compression fractures.

The present study showed that a higher rehabilitation treatment intensity per day was significantly associated with better BI scores at discharge, whereas the frequency of rehabilitation treatment was not associated with better BI scores at discharge. Higher frequency and higher intensity of rehabilitation treatment were found to be effective in improving function among patients who had undergone hip fracture surgery. ${ }^{11,30,31)}$ That result was partly in accordance with our findings. ${ }^{11,30,31)}$ The difference with respect to the frequency of rehabilitation treatment could have resulted from the lack of detailed information on rehabilitation treatment programs in the present study, and the programs may have varied based on the number of days after admission or the clinical condition of the patient. Future studies must be conducted to identify the differential effects of different types and intensities of rehabilitation treatment.

Older patients who underwent conservative treatment for vertebral compression fractures required long-term treatment, ${ }^{32)}$ and the presence of existing vertebral compression fractures was found to increase the risk of recurrence. ${ }^{33)}$ As a result, appropriate treatments are necessary for maximizing health-related outcomes. Furthermore, vertebral compression fractures are common complications of osteoporosis. ${ }^{3,5)}$ Previous studies have indicated that rehabilitation treatment is effective in improving bone density. Additionally, early rehabilitation treatment is beneficial for patients with various orthopedic diseases. ${ }^{9-11,27)}$ When integrating these findings, early rehabilitation treatment could play a vital role in the management of patients with vertebral compression fractures who undergo conservative treatment.

The coefficient for the association between the interval between admission and the start of rehabilitation treatment and BI at discharge indicated that BI was 2.71 lower for each day that the initiation of rehabilitation treatment was delayed among patients admitted (pre) weekend. However, the magnitude of the association with early rehabilitation treatment was smaller than that of the per-day intensity of in-hospital 
rehabilitation treatment. Moreover, a similar coefficient value was obtained when using the improvement in BI as the outcome (coefficient $=-2.72$, Supplementary Table 4), which is also smaller than the minimal detectable change in the $\mathrm{BI}$ in older patients (i.e., 15 points). ${ }^{21)}$ Consequently, the intensity of daily rehabilitation treatment plays an important role in hospitalized older patients receiving conservative treatment for vertebral compression fractures in the acute phase. In other words, our findings suggest that intensive rehabilitation treatment is beneficial for improving ADL at discharge, even if it is not implemented immediately after admission.

This study has several limitations. First, other factors, including the severity of pain or weakness before admission, were not evaluated because that information was not available in the database. Therefore, the effects of early initiation of rehabilitation treatment might differ depending on patients' pain levels and degree of frailty. However, in our regression models, we included several variables (admission by ambulance, length of hospital stay, use of home health care services, nursing facility resident) that likely reflected the severity of disease. Moreover, we conducted several sensitivity analyses, all of which had consistent results (Supplementary Table 8). Second, because this was a retrospective observational study, it could have been affected by unknown or unmeasured confounders, including socioeconomic factors. Although we used the IV method to make the current study more closely mimic an RCT, the validity of the IV method in this study has not been definitively proven. Third, detailed information about the rehabilitation treatment programs was not available. However, rehabilitation treatment programs for acute vertebral compression fractures usually comprise (1) therapeutic exercises, which are aimed at reducing pain and improving bone density, and (2) education, which is aimed at improving posture and body mechanics to reduce vertical compressive loads and prevent future fractures. ${ }^{29)}$ Fourth, the generalizability of the current results may be limited because our study was conducted in one prefecture of Japan. The proportion of older people in Yamagata Prefecture is higher than that for Japan as a whole (30.8\% vs. $26.6 \%$, in 2015). ${ }^{34)}$ Nonetheless, the duration of hospital stay was similar to that of Japanese national standards (26.8 days vs. 29.3 days, in 2017). ${ }^{35)}$ Additionally, the generalizability of our findings to other countries might be limited because of differing lengths of hospital stay. The length of hospital stay in Japan is longer than that of the US or European countries ${ }^{36)}$; consequently, our results are more likely to be influenced by the intensity of daily rehabilitation treatment.
In conclusion, delay in starting rehabilitation treatment had a negative effect on ADL at discharge in patients with vertebral compression fractures who received conservative rehabilitation treatment. Our findings emphasize the importance of including early rehabilitation treatment in acute care, as recommended by several existing guidelines for the treatment of orthopedic diseases.

\section{ACKNOWLEDGMENTS}

This work was supported by the Japan Society for the Promotion of Science (JSPS) KAKENHI Grant Number (19K19818, Takaaki Ikeda) and the Taiju Life Social Welfare Foundation (Takaaki Ikeda). No sponsor had any role in the design or conduct of the study; collection, management, analysis, or interpretation of the data; preparation, review, or approval of the manuscript; or the decision to submit the manuscript for publication.

\section{CONFLICTS OF INTEREST}

The authors have no financial competing interests.

\section{REFERENCES}

1. Cummings SR, Black DM, Thompson DE, Applegate WB, Barrett-Connor E, Musliner TA, Palermo L, Prineas R, Rubin SM, Scott JC, Vogt T, Wallace R, Yates AJ, LaCroix AZ: Effect of alendronate on risk of fracture in women with low bone density but without vertebral fractures: results from the Fracture Intervention Trial. JAMA 1998;280:2077-2082. DOI:10.1001/ jama.280.24.2077, PMID:9875874

2. Varacallo MA, Fox EJ: Osteoporosis and its complications. Med Clin North Am 2014;98:817-831, xii-xiii. DOI:10.1016/j.mcna.2014.03.007, PMID:24994054

3. Johnell O, Kanis JA: An estimate of the worldwide prevalence and disability associated with osteoporotic fractures. Osteoporos Int 2006;17:1726-1733. DOI:10.1007/s00198-006-0172-4, PMID:16983459

4. Tosteson AN, Gabriel SE, Grove MR, Moncur MM, Kneeland TS, Melton LJ III: Impact of hip and vertebral fractures on quality-adjusted life years. Osteoporos Int 2001;12:1042-1049. DOI:10.1007/s001980170015, PMID:11846331 
5. Wong CC, McGirt MJ: Vertebral compression fractures: a review of current management and multimodal therapy. J Multidiscip Healthc 2013;6:205-214. PMID:23818797

6. American Physical Therapy Association: Early mobilization reduces the risk of adverse events and improves function: research on the value of physical therapy. 2019 [cited 2019 Feb 23]. Available from: https://www. apta.org/uploadedFiles/APTAorg/Payment/Medicare/ Coding_and_Billing/Research-PT-Value-Early-Mobilization.pdf

7. National Clinical Guideline Centre: The management of hip fracture in adults. [cited 2019 Sep 23]. Available from: https://www.nice.org.uk/guidance/cg124

8. Scottish Intercollegiate Guidelines Network: Management of hip fracture in older people - A national clinical guideline. 2009. [cited 2019 Feb 23]. Available from: https://www.sign.ac.uk/assets/sign111.pdf

9. Adogwa O, Elsamadicy AA, Fialkoff J, Cheng J, Karikari IO, Bagley C: Early ambulation decreases length of hospital stay, perioperative complications and improves functional outcomes in elderly patients undergoing surgery for correction of adult degenerative scoliosis. Spine 2017;42:1420-1425. DOI:10.1097/ BRS.0000000000002189, PMID:28902101

10. Carpintero P, Caeiro JR, Carpintero R, Morales A, Silva S, Mesa M: Complications of hip fractures: a review. World J Orthop 2014;5:402-411. DOI:10.5312/ wjo.v5.i4.402, PMID:25232517

11. Uda K, Matsui H, Fushimi K, Yasunaga H: Intensive in-hospital rehabilitation after hip fracture surgery and activities of daily living in patients with dementia: retrospective analysis of a nationwide inpatient database. Arch Phys Med Rehabil 2019;100:2301-2307. DOI:10.1016/j.apmr.2019.06.019, PMID:31421098

12. Goldstein CL, Chutkan NB, Choma TJ, Orr RD: Management of the elderly with vertebral compression fractures. Neurosurgery 2015;77(Suppl 4):S33-S45. DOI:10.1227/NEU.0000000000000947, PMID:26378356

13. Kobata $\mathrm{T}$, Hasebe $\mathrm{K}$, Momosaki R: Effectiveness of early rehabilitation for vertebral compression fractures: a retrospective cohort study. J Geriatr Phys Ther 2021;44:139-143. DOI:10.1519/ JPT.0000000000000267, PMID:32282616
14. Bound J, Jaeger DA, Baker RM: Problems with instrumental variables estimation when the correlation between the instruments and the endogenous explanatory variable is weak. J Am Stat Assoc 1995;90:443-450. DOI:10.1080/01621459.1995.10476536

15. Greenland S: An introduction to instrumental variables for epidemiologists. Int J Epidemiol 2000;29:722-729. DOI:10.1093/ije/29.4.722, PMID:10922351

16. Yamagata Prefecture: Reports on function of hospital beds in Yamagata Prefecture. 2018. [cited 2019 Feb 23]. Available from: http://www.pref.yamagata.jp/medicalnet/byousyouhoukoku29/

17. Yasunaga H, Matsui H, Horiguchi H, Fushimi K, Matsuda S: Clinical epidemiology and health services research using the Diagnosis Procedure Combination database in Japan. Asian Pac J Dis Manag 2015;7:19 24. DOI:10.7223/apjdm.7.19

18. Ministry of Health Labour and Welfare: Length of hospital stays by diagnosis group classification. 2018 [cited 2021 Jul 1]. Available from: https://www.mhlw. go.jp/stf/seisakunitsuite/bunya/0000198757.html

19. Mahoney FI, Barthel DW: Functional evaluation: The Barthel Index. Md State Med J 1965;14:61-65. PMID:14258950

20. Oveisgharan S, Shirani S, Ghorbani A, Soltanzade A, Baghaei A, Hosseini S, Sarrafzadegan N: Barthel Index in a Middle-East country: translation, validity and reliability. Cerebrovasc Dis 2006;22:350-354. DOI:10.1159/000094850, PMID:16888374

21. Bouwstra H, Smit EB, Wattel EM, van der Wouden JC, Hertogh CM, Terluin B, Terwee CB: Measurement properties of the Barthel Index in geriatric rehabilitation. J Am Med Dir Assoc 2019;20:420-425.e1. DOI:10.1016/j.jamda.2018.09.033, PMID:30448338

22. Quan H, Sundararajan V, Halfon P, Fong A, Burnand B, Luthi JC, Saunders LD, Beck CA, Feasby TE, Ghali WA: Coding algorithms for defining comorbidities in ICD-9-CM and ICD-10 administrative data. Med Care 2005;43:1130-1139. DOI:10.1097/01. mlr.0000182534.19832.83, PMID:16224307

23. Tsuboi A, Murakami T, Kurumadani H, Shimizu J, Fujiwara N: Relationship between criteria for evaluating the degree of independence of disabled elderly persons in performing activities of daily living [in Japanese]. J Jpn Occup Ther Assoc. 2002;21:455-462. 
24. Brookhart MA, Rassen JA, Schneeweiss S: Instrumental variable methods in comparative safety and effectiveness research. Pharmacoepidemiol Drug Saf 2010;19:537-554. DOI:10.1002/pds.1908, PMID:20354968

25. Sasabuchi Y, Matsui H, Lefor AK, Fushimi K, Yasunaga H: Timing of surgery for hip fractures in the elderly: a retrospective cohort study. Injury 2018;49:1848-1854. DOI:10.1016/j.injury.2018.07.026, PMID:30097309

26. Rubin DB, Schenker N: Multiple imputation for interval estimation from surveys with ignorable nonresponse. J Am Stat Assoc 1985;81:366-374. DOI:10.1080/0162145 9.1986.10478280

27. Quadlbauer S, Pezzei C, Jurkowitsch J, Kolmayr B, Keuchel T, Simon D, Hausner T, Leixnering M: Early rehabilitation of distal radius fractures stabilized by volar locking plate: a prospective randomized pilot study. J Wrist Surg 2017;6:102-112. PMID:28428911

28. Pérez-Schindler J, Handschin C: Physiological regulation of skeletal muscle mass. Nutr Skelet Muscle 2019;27:139-150. DOI:10.1016/B978-0-12-8104224.00011-7

29. Prather H, Van Dillen L, Metzler JP, Riew KD, Gilula LA: Prospective measurement of function and pain in patients with non-neoplastic compression fractures treated with vertebroplasty. J Bone Joint Surg Am 2006;88:334-341. PMID:16452745

30. Lee SY, Yoon BH, Beom J, Ha YC, Lim JY: Effect of lower-limb progressive resistance exercise after hip fracture surgery: a systematic review and metaanalysis of randomized controlled studies. J Am Med Dir Assoc 2017;18:1096.e19-1096.e26. DOI:10.1016/j. jamda.2017.08.021, PMID:29033325
31. Hauer K, Specht N, Schuler M, Bärtsch P, Oster P: Intensive physical training in geriatric patients after severe falls and hip surgery. Age Ageing 2002;31:49-57. DOI:10.1093/ageing/31.1.49, PMID:11850308

32. Lee HM, Park SY, Lee SH, Suh SW, Hong JY: Comparative analysis of clinical outcomes in patients with osteoporotic vertebral compression fractures (OVCFs): conservative treatment versus balloon kyphoplasty. Spine J 2012;12:998-1005. DOI:10.1016/j. spinee.2012.08.024, PMID:23026068

33. Fujiwara S, Kasagi F, Masunari N, Naito K, Suzuki G, Fukunaga M: Fracture prediction from bone mineral density in Japanese men and women. J Bone Miner Res 2003;18:1547-1553. DOI:10.1359/jbmr.2003.18.8.1547, PMID:12929946

34. Portal Site for Japanese Government Statistics. Population Census. 2015 [cited 2019 Dec 20]. Available from: https://www.e-stat.go.jp/stat-search/file-download?stat InfId $=000031594311 \&$ fileKind $=0$

35. Portal Site for Japanese Government Statistics. Patient Survey. 2017 [cited 2019 Dec 20]. Available from: https://www.e-stat.go.jp/stat-search/file-download?stat InfId $=000031790707 \&$ fileKind $=1$

36. Ong T, Kantachuvesiri P, Sahota O, Gladman JR: Characteristics and outcomes of hospitalised patients with vertebral fragility fractures: a systematic review. Vol. 47, Age and Ageing. Oxford University Press; 2018. 17-25. 
Supplementary Table 1 . Subgroup analysis (only patients with osteoporosis were included)

\begin{tabular}{lccccc}
\hline Type of subgroup analysis & $\beta$ & \multicolumn{2}{c}{$95 \%$ CI } & P-value & $F$-statistic \\
\hline $\begin{array}{l}\text { Analysis of patients aged } \geq 65 \text { years and length of } \\
\text { hospital stay } \leq 30 \text { days }(\mathrm{n}=748)\end{array}$ & -4.89 & -9.69 & -0.10 & 0.045 & 18.1 \\
$\begin{array}{l}\text { Analysis of patients aged } \geq 65 \text { years and length of } \\
\text { hospital stay } \leq 60 \text { days }(\mathrm{n}=1271)\end{array}$ & -3.04 & -5.77 & -0.31 & 0.03 & 15.9 \\
$\begin{array}{l}\text { Analysis of patients aged } \geq 65 \text { years and length of } \\
\text { hospital stay } \leq 90 \text { days }(\mathrm{n}=1450)\end{array}$ & -3.13 & -6.17 & -0.10 & 0.04 & 17.6 \\
\hline
\end{tabular}

Patients with osteoporosis were included in the analyses (multiply imputed data).

The models were adjusted for age, sex, site of fracture, Barthel index score at admission, Charlson comorbidity index score, residence before admission, BMI at admission, use of home health care services before admission, level of dementia, length of hospital stay, admission by ambulance, and frequency/intensity of in-hospital rehabilitation treatment.

Clustering of standard errors within hospitals was considered.

Supplementary Table 2. Sensitivity analysis of patients hospitalized for $\leq 60$ days

\begin{tabular}{|c|c|c|c|c|c|}
\hline Type of sensitivity analysis & $\beta$ & \multicolumn{2}{|c|}{$95 \% \mathrm{CI}$} & P-value & $F$-statistic \\
\hline Multiple imputation analysis $(n=2635)$ & -2.02 & -3.84 & -0.20 & 0.03 & 28.0 \\
\hline Best-case imputation* $(n=2176)$ & -2.32 & -4.41 & -0.22 & 0.03 & 31.0 \\
\hline Best-case imputation** $(n=2635)$ & -1.83 & -3.93 & 0.28 & 0.09 & 42.9 \\
\hline Worst-case imputation $^{\dagger}(\mathrm{n}=2176)$ & -2.22 & -4.29 & -0.16 & 0.03 & 28.5 \\
\hline Worst-case imputation $*(n=2635)$ & -2.07 & -4.82 & 0.69 & 0.14 & 43.1 \\
\hline Complete case analysis $(n=1169)$ & -2.12 & -5.99 & 1.76 & 0.29 & 16.7 \\
\hline
\end{tabular}

The models were adjusted for age, sex, site of fracture, Barthel index score at admission, Charlson comorbidity index score, residence before admission, BMI at admission, use of home health care services before admission, level of dementia, length of hospital stay, admission by ambulance, and frequency/intensity of in-hospital rehabilitation treatment.

Clustering of standard errors within hospitals was considered.

* Missing values for the Barthel index at admission, BMI at admission, and use of home health care services before admission were set to 100 (good score), 18.5-24.9, and no, respectively.

** Missing values for the Barthel index at admission, BMI at admission, and use of home health care services before admission were set to 100 (good score), 18.5-24.9, and no, respectively. Furthermore, missing values for the Barthel index score at discharge were set to 100 (good score).

$\dagger$ Missing values for the Barthel index at admission, BMI at admission, and use of home health care services before admission were set to 0 (poor score), $<18.5$, and yes, respectively.

+ Missing values for the Barthel index at admission, BMI at admission, and use of home health care services before admission were set to 0 (poor score), $<18.5$, and yes, respectively. Furthermore, missing values for the Barthel index at discharge were set to 0 (poor score). 
Supplementary Table 3. Sensitivity analysis of patients hospitalized for $\leq 90$ days

\begin{tabular}{|c|c|c|c|c|c|}
\hline Type of sensitivity analysis & $\beta$ & \multicolumn{2}{|c|}{$95 \% \mathrm{CI}$} & P-value & $F$-statistic \\
\hline Multiple imputation analysis $(n=2923)$ & -1.93 & -3.90 & -0.02 & 0.048 & 23.3 \\
\hline Best-case imputation* $(n=2420)$ & -2.27 & -4.35 & -0.19 & 0.03 & 28.3 \\
\hline Best-case imputation** $(n=2923)$ & -1.59 & -3.49 & 0.30 & 0.10 & 36.5 \\
\hline Worst-case imputation $^{\dagger}(\mathrm{n}=2420)$ & -2.15 & -4.26 & -0.05 & 0.045 & 25.8 \\
\hline Worst-case imputation $*(n=2923)$ & -2.15 & -5.00 & 0.70 & 0.14 & 35.6 \\
\hline Complete case analysis $(n=1333)$ & -2.61 & -6.33 & 1.12 & 0.17 & 17.8 \\
\hline
\end{tabular}

The models were adjusted for age, sex, site of fracture, Barthel index score at admission, Charlson comorbidity index score, residence before admission, BMI at admission, use of home health care services before admission, level of dementia, length of hospital stay, admission by ambulance, and frequency/intensity of in-hospital rehabilitation treatment.

Clustering of standard errors within hospitals was considered.

* Missing values for the Barthel index at admission, BMI at admission, and use of home health care services before admission were set to 100 (good score), 18.5-24.9, and no, respectively.

** Missing values for the Barthel index at admission, BMI at admission, and use of home health care services before admission were set to 100 (good score), 18.5-24.9, and no, respectively. Furthermore, missing values for the Barthel index score at discharge were set to 100 (good score).

$\dagger$ Missing values for the Barthel index at admission, BMI at admission, and use of home health care services before admission were set to 0 (poor score), $<18.5$, and yes, respectively.

\$ Missing values for the Barthel index at admission, BMI at admission, and use of home health care services before admission were set to 0 (poor score), $<18.5$, and yes, respectively. Furthermore, missing values for the Barthel index at discharge were set to 0 (poor score).

Supplementary Table 4. Sensitivity analysis (the improvement in Barthel index was used as the outcome, multiple imputation analysis)

\begin{tabular}{lccccc}
\hline & $\beta$ & \multicolumn{2}{c}{$95 \%$ CI } & P-value & $F$-statistic \\
\hline $\begin{array}{l}\text { Analysis of patients aged } \geq 65 \text { years and length of } \\
\text { hospital stay } \leq 30 \text { days }(\mathrm{n}=1706)\end{array}$ & -2.72 & -5.08 & -0.36 & 0.02 & 19.0 \\
$\begin{array}{l}\text { Analysis of patients aged } \geq 65 \text { years and length of } \\
\text { hospital stay } \leq 60 \text { days }(\mathrm{n}=2635)\end{array}$ & -2.02 & -3.85 & -0.18 & 0.03 & 25.3 \\
$\begin{array}{l}\text { Analysis of patients aged } \geq 65 \text { years and length of } \\
\text { hospital stay } \leq 90 \text { days }(\mathrm{n}=2923)\end{array}$ & -1.93 & -3.90 & 0.04 & 0.054 & 22.1 \\
\hline
\end{tabular}

The models were adjusted for age, sex, site of fracture, Barthel index score at admission, Charlson comorbidity index score, residence before admission, BMI at admission, use of home health care services before admission, level of dementia, length of hospital stay, admission by ambulance, and frequency/intensity of in-hospital rehabilitation treatment.

Clustering of standard errors within hospitals was considered.

Supplementary Table 5. Subgroup analysis (patients aged $\geq 75$ years)

\begin{tabular}{lccccc}
\hline Type of subgroup analysis & $\beta$ & \multicolumn{2}{c}{$95 \%$ CI } & P-value & $F$-statistic \\
\hline $\begin{array}{l}\text { Analysis of patients aged } \geq 75 \text { years and length of } \\
\text { hospital stay } \leq 30 \text { days }(\mathrm{n}=1415)\end{array}$ & -2.68 & -5.51 & 0.15 & 0.06 & 16.1 \\
$\begin{array}{l}\text { Analysis of patients aged } \geq 75 \text { years and length of } \\
\text { hospital stay } \leq 60 \text { days }(\mathrm{n}=2233)\end{array}$ & -2.07 & -4.21 & 0.07 & 0.06 & 34.8 \\
$\begin{array}{l}\text { Analysis of patients aged } \geq 75 \text { years and length of } \\
\text { hospital stay } \leq 90 \text { days }(\mathrm{n}=2489)\end{array}$ & -1.86 & -4.10 & 0.39 & 0.11 & 32.5 \\
\hline
\end{tabular}

Only patients aged $\geq 75$ years were included in the analyses (multiply imputed data).

The models were adjusted for age, sex, site of fracture, Barthel index score at admission, Charlson comorbidity index score, residence before admission, BMI at admission, use of home health care services before admission, level of dementia, length of hospital stay, admission by ambulance, and frequency/intensity of in-hospital rehabilitation treatment.

Clustering of standard errors within hospitals was considered. 
Supplementary Table 6. Admission by ambulance and the Barthel index at discharge with the Barthel index at admission

\begin{tabular}{|c|c|c|c|c|c|c|c|}
\hline & & \multicolumn{6}{|c|}{ Barthel index at admission } \\
\hline & & \multicolumn{2}{|c|}{$\begin{array}{c}<100 \\
\text { (dependent) }\end{array}$} & \multicolumn{2}{|c|}{100 (independent) } & \multicolumn{2}{|c|}{ Missing data } \\
\hline & & $\mathrm{n}$ & $\%$ & $\mathrm{n}$ & $\%$ & $\mathrm{n}$ & $\%$ \\
\hline \multirow[t]{2}{*}{ Admission by ambulance } & No & 1068 & 55.1 & 180 & 9.3 & 690 & 35.6 \\
\hline & Yes & 614 & 43.6 & 100 & 7.1 & 693 & 49.3 \\
\hline \multirow[t]{3}{*}{ Barthel index at discharge } & $<100$ (dependent) & 1150 & 58.2 & 80 & 4.1 & 747 & 37.8 \\
\hline & 100 (independent) & 379 & 46.1 & 168 & 20.4 & 275 & 33.5 \\
\hline & Missing data & 153 & 28.0 & 32 & 5.9 & 361 & 66.1 \\
\hline
\end{tabular}

The number of patients represented in this table is 3345 because patients aged $\leq 64$ years and those who remained in hospital for $>30$ days were included.

Supplementary Table 7. Spearman's correlation coefficients between variables

\begin{tabular}{|c|c|c|c|c|c|c|c|c|c|c|c|c|}
\hline & $\begin{array}{c}\text { BI at } \\
\text { dis- } \\
\text { charge }\end{array}$ & $\begin{array}{c}\text { BI at } \\
\text { admis- } \\
\text { sion }\end{array}$ & $\mathrm{LOH}$ & $\begin{array}{c}\text { Ambu- } \\
\text { lance } \\
\text { use }\end{array}$ & Sex & Age & $\begin{array}{l}\text { Resi- } \\
\text { dence }\end{array}$ & $\begin{array}{c}\text { Hospi- } \\
\text { tal }\end{array}$ & $\begin{array}{c}\text { Home } \\
\text { health } \\
\text { care }\end{array}$ & $\begin{array}{l}\text { Osteo- } \\
\text { porosis }\end{array}$ & $\begin{array}{c}\text { De- } \\
\text { mentia }\end{array}$ & BMI \\
\hline $\mathrm{BI}$ at discharge & 1.00 & & & & & & & & & & & \\
\hline $\mathrm{BI}$ at admission & $0.38^{*}$ & 1.00 & & & & & & & & & & \\
\hline $\mathrm{LOH}$ & -0.03 & $-0.10^{*}$ & 1.00 & & & & & & & & & \\
\hline Ambulance use & $-0.12 *$ & $-0.27^{*}$ & -0.04 & 1.00 & & & & & & & & \\
\hline Sex & -0.09 & -0.04 & $0.06^{*}$ & $-0.09 *$ & 1.00 & & & & & & & \\
\hline Age & $-0.42^{*}$ & $-0.14^{*}$ & $0.15^{*}$ & 0.00 & $0.17^{*}$ & 1.00 & & & & & & \\
\hline Residence & $-0.15^{*}$ & $-0.07^{*}$ & 0.03 & -0.03 & $0.07^{*}$ & $0.12 *$ & 1.00 & & & & & \\
\hline Hospital & $0.12^{*}$ & $0.24 *$ & $0.08 *$ & -0.02 & 0.02 & -0.04 & $-0.07 *$ & 1.00 & & & & \\
\hline Home health care & $-0.13^{*}$ & $-0.09 *$ & 0.01 & -0.01 & -0.02 & $0.08 *$ & $0.07 *$ & -0.01 & 1.00 & & & \\
\hline Osteoporosis & -0.03 & -0.05 & $0.14 *$ & $-0.08^{*}$ & $0.24 *$ & $0.09 *$ & -0.02 & $0.08^{*}$ & -0.01 & 1.00 & & \\
\hline Dementia & $-0.31^{*}$ & $-0.13^{*}$ & $0.21^{*}$ & 0.00 & $0.10^{*}$ & $0.41^{*}$ & $0.14^{*}$ & $0.12 *$ & $0.11^{*}$ & $0.11^{*}$ & 1.00 & \\
\hline BMI & $0.11 *$ & $0.05 *$ & $-0.06^{*}$ & -0.01 & $-0.06^{*}$ & $-0.18 *$ & 0.00 & -0.03 & -0.04 & $-0.07 *$ & $-0.16^{*}$ & 1.00 \\
\hline
\end{tabular}

The number of patients represented in this table is 3345 because patients aged $\leq 64$ years and those who remained in hospital for $>30$ days were included.

$\mathrm{LOH}$, length of hospital stay.

$* \mathrm{P}<0.05$. 
Supplementary Table 8. Sensitivity analysis of patients hospitalized for $\leq 30$ days

\begin{tabular}{|c|c|c|c|c|c|}
\hline Type of sensitivity analysis & $\beta$ & \multicolumn{2}{|c|}{$95 \% \mathrm{CI}$} & P-value & $F$-statistic \\
\hline Best-case imputation* $(\mathrm{n}=1381)$ & -3.07 & -5.83 & -0.30 & 0.03 & 21.2 \\
\hline Best-case imputation** $(n=1706)$ & -2.61 & -5.07 & -0.16 & 0.04 & 31.0 \\
\hline Worst-case imputation $^{\dagger}(\mathrm{n}=1381)$ & -2.92 & -5.72 & -0.14 & 0.04 & 19.8 \\
\hline Worst-case imputation $\star(n=1706)$ & -3.04 & -6.36 & 0.29 & 0.07 & 31.2 \\
\hline Complete case analysis $(n=703)$ & -4.80 & -10.23 & 0.63 & 0.08 & 14.0 \\
\hline
\end{tabular}

The models were adjusted for age, sex, site of fracture, Barthel index score at admission, Charlson comorbidity index score, residence before admission, BMI at admission, use of home health care services before admission, level of dementia, length of hospital stay, admission by ambulance, and frequency/intensity of in-hospital rehabilitation treatment.

Clustering of standard errors within hospitals was considered.

* Missing values for the Barthel index at admission, BMI at admission, and use of home health care services before admission were set to 100 (good score), 18.5-24.9, and no, respectively.

** Missing values for the Barthel index at admission, BMI at admission, and use of home health care services before admission were set to 100 (good score), 18.5-24.9, and no, respectively. Furthermore, missing values for the Barthel index score at discharge were set to 100 (good score).

$\dagger$ Missing values for the Barthel index at admission, BMI at admission, and use of home health care services before admission were set to 0 (poor score), $<18.5$, and yes, respectively.

\$ Missing values for the Barthel index at admission, BMI at admission, and use of home health care services before admission were set to 0 (poor score), $<18.5$, and yes, respectively. Furthermore, missing values for the Barthel index at discharge were set to 0 (poor score). 